\title{
The brain-mind quiddity: ethical issues in the use of human brain tissue for therapeutic and scientific purposes
}

\author{
Larry Burd, Jennifer M Gregory and Jacob Kerbeshian University of North Dakota, USA
}

\begin{abstract}
The use of human brain tissue in neuroscience research is increasing. Recent developments include transplanting neural tissue, growing or maintaining neural tissue in laboratories and using surgically removed tissue for experimentation. Also, it is likely that in the future there will be attempts at partial or complete brain transplants. A discussion of the ethical issues of using human brain tissue for research and brain transplantation has been organized around nine broadly defined topic areas. Criteria for human brain tissue transplantation and laboratory use of brain tissue are proposed.

(Fournal of Medical Ethics 1998;24:118-122)
\end{abstract}

Keywords: Brain transplantation; neuroscience; personhood; life; ethics; brain; mind

In a previous issue of the journal, Dr Gillon's editorial provided a framework and commentary as a companion piece to an article by Dr Northoff on ethical issues of brain transplantation. ${ }^{12}$ These articles provided an important first step for discussion of the philosophical and ethical issues surrounding brain transplantation. In this paper we wish to add to this ongoing discussion and to describe several additional relevant areas in this discussion. These issues relate to development of the mind-brain duality, personhood, and selfidentity. The 1990s have been designated as the "Decade of the Brain" to recognize both the tremendous progress that has been made in the basic and clinical neurosciences and to call attention to the work yet to be done. ${ }^{3}$ Late into this decade important advances have revealed insights into the molecular basis of several neurological disorders, for example, the diagnosis of Huntington's Chorea and Fragile X Syndrome. Impressive advances have accompanied these basic science efforts in the understanding of functioning of the central nervous system. Functional imaging studies have substantially enhanced the scientific understanding of brain organization. However, relatively little parallel progress has been made in understanding the unique construct of brain activity which we call "the mind". This term, "the mind", is the conceptual vehicle used to commuip nicate many of the brain activities which have yer defied either anatomical or functional localization $n_{0}^{\infty}$ In some people with substantial amounts of miss? ing brain tissue all of these activities occur. Othe $\vec{s}$ people with apparently normal brains demon strate very few of these activities. Although the role of individual parts of the brain remains poorly understood neuroscience seems posed to make remarkable progress in the near future. A receno development in clinical neuroscience has been the isolation and laboratory growth of brain tissue cefo lines in laboratories around the world. ${ }^{4}$ Thes efforts at the cellular level and the whole brain o total body transplants in animals completed morf than three decades ago by White and colleagues seem certain to be the focus of increasing emphae. sis from neuroscientists in the future. Thes strategies offer attractive methodologies for reథ searchers and clinicians who seek to ameliorate the sequelae of human central nervous system. disease and dysfunction. ${ }^{6-8}$ In contrast to the suc을 cess in animals of head transplants, the curren 5 science base suggests that mature cerebral tissue in large blocks cannot be homotransplanted inte mature brains. ${ }^{78}$ These efforts at the cellular leveit on the one hand and at the level of whole brain transplants (limited to animals to date) on the other, give rise to nine important ethical, sociak, and scientific questions which are the focus of thi discussion:

1 Is it possible to grow brain tissue without the occurrence of corresponding mind (mentaly activities?

2 If activity is present in this tissue, does support a mind-brain unit and as a result generate emotions, sensations, or other internally gener ated brain activity?

3 Should developmental experience be a criterio for the brain-mind unit to have the qualities of person? 
4 Might brain tissue separated from a body manifest fear, hopelessness, euphoria or creativity? 5 Does the brain-mind unit need a body to have the qualities of a person?

6 If mental activities occur in laboratory brain tissue specimens, how would these activities be detectable?

7 If the mind-brain unit is present in laboratory brain tissue specimens should these laboratory specimens be used to study mental activities?

8 Can a person give consent for his or her brain tissue to be grown or maintained in a laboratory setting if the tissue had or later develops the independent capacity to respond at some level?

9 Should a human subjects institutional review board review these activities and how could such a board determine when a person is being studied rather than a collection of neurons?

1) Is it possible to grow brain tissue without the occurrence of corresponding mind activities? There are several useful measures of brain activity and the absence of these are the most useful criteria for the diagnosis of brain death. ${ }^{9}$ The criteria for clinical death in use today refer to loss of function of both the brain and the mind. ${ }^{10}$ Brain death results in a cessation of the brain-mind duality and the loss of personhood that makes possible the use of all body parts for donation, experimental dissection, or simply burial. Relatively little discussion has taken place about the maintenance or growth of brain tissue in laboratory settings. Brain tissue grown in a laboratory dish is alive or dead. The "alive" state implies that the cells are at some level functional and responsive. The cells have metabolism and demonstrate some actions similar to cells that are a part of the human brain when it is functional. It is obvious that whole brains are not required for mental activity and psychological development to occur. Herein resides the quiddity of the mind-brain relationship. Are they, mind and brain, always biologically and functionally linked? There is no evidence that mental activity exists without brain tissue. But, does living brain tissue always equate to mental activity? From an ethical and philosophical view is the relationship of brain $\rightarrow$ neural activity $\rightarrow$ mental activity (mind) always present. Or is the relationship trivial for small amounts of brain tissue where the equation could be stated brain $\rightarrow$ neural activity (neurochemical and electrical organization) $\neq$ mental activity (mind)?

2) If activity is present in brain tissue does it support a mind-brain unit and as a result generate emotions, sensations or internally generated mental activity? While the boundary between life and death can be difficult to define and has been the subject of numerous legal, moral, and ethical debates, this discussion looks the other way. At what level of brain activity is the mind functional? If the absence of this activity defines brain death does the presence of brain activity define life? The brain is a neural structure which develops very early in pregnancy, and continues to develop throughout pregnancy and in the first years of life. The brain assumes control over a number of extremely important functions and becomes responsive to changes in the environment very early in the developmental period. If removed from the head and maintained would brain tissue have similar functional capacities? Could this tissue support mental activities? In what way are the individual neurons grown in a culture different from the neurons that comprise the brain of an airline pilot struggling to land a damaged plane, a first-grader walking home imagining the birthday presents he will receive tomorrow at his party, or of a physician walking into his office to tell one of his close friends that the friend has a fatal illness? Using the fictitious case of Susan referred to by Gillon, ${ }^{1}$ questions 1) and 2) ask when does a collection of brain tissue become large enough or have sufficiently organized neurophysiological activity to develop mental activities and become a "Susan".

3) Should developmental experience be a criterion for the brain-mind unit to have the qualities of a person? If a large number of neurons can be grown in the laboratory setting and then develop organized neural activity, could one argue that the lack of developmental experience prevents this brain tissue from achieving mental activities? Would a lack of developmental experience preclude personhood status so that the tissue would always remain just tissue? Must brain tissue be attached to a body for developmental experience to occur?

4) Might brain tissue separated from a body manifest mental experiences of fear, hopelessness, euphoria or creativity? The constructs used to describe or define many mind-brain activities are poorly delineated but at their extremes easily recognized. The functional limitations of people with profound mental retardation or the prodigious capacity demonstrated by persons with savant skills are easily recognized. People demonstrate a wide range of responses to what appear to be virtually identical injuries. In the locked-in syndrome a person is unable to express himself while his brain has considerable functional capacity. ${ }^{11}$ This condition is surely amongst the most tragic of those which afflict human beings. During general anaesthetic for surgery brain activity is markedly reduced but, because of the reversibility of this 
temporary state the persons and their bodies are treated with considerable dignity. However, the same person, when brain dead, could be used to demonstrate anatomy over a period of weeks to first-year medical students, be cremated or buried. White and colleagues have removed the brain from the head of a monkey and kept this brain in a container for several days and the monkey brain had an organized electroencephalographic (EEG) tracing. ${ }^{6}$ If a similar operation on a person produced a human brain outside of the body in a container with functional EEG tracings what would be the status of the former person and the present brain tissue? Could a brain in a container produce mental activity sufficiently organized to produce psychological states? Even more important could this brain experience fear, anxiety, pain as neuropsychological events? Would the status change if an eye or ear were left attached so the brain could perceive and respond to external stimuli?

5) Does the brain-mind unit need a body to have the qualities of a person? Does attachment to a body confer on the brain-mind unit special organ considerations and separate brain tissue from other organs like a kidney or lung? This question is central to the ethical quiddity of the mind-brain relationship. The perceptual limitations seen in persons with blindness, deafness, high level spinal cord injuries or people afflicted with locked-in syndrome, does not alter society's recognition that these people are alive. ${ }^{9}$ Gillon argues that transplanting Susan's brain into George's body would produce Susan in a different body. A potential first step in such a theoretical endeavour might well be similar to the procedures used by Demikhov. ${ }^{12}$ In these animal experiments he grafted the head of one animal onto the upper torso of another. He published pictures of a dog with two heads, both lapping milk out of a bowl. If a normally functioning head was transplanted onto the person of a profoundly retarded person what would be the status of both minds? Which person would predominate - the higher functioning head or the intact brain-body unit? Could one body be two persons? As we discussed above what is the status of living brain tissue separated from a body? And lastly an interesting question in the "Decade of the Brain" is whose health insurance would cover the cost of care, Susan's or George's? 6) If "mind" activities occur in a laboratory sample of brain tissue how would these activities be detectable? It is the presence of activity (response) in this collection of neurons in the laboratory that makes them so valued. If the lack of capacity for recovery or change defines death what attributes does the capacity to respond and change confer on neurons in a laboratory dish? Would our attitu华 change if neurons or brain tissue had the capacia for such response? For example, what if the collection of neurons could produce specific EE changes unique to certain stimuli? How woufd life-personhood be defined for this tissue entity? 7) If the brain-mind unit is present in laborato brain tissues should these laboratory specimens used to study mental activities? Could one of these tissue samples experience fear, anxiety or other psychological constructs used to describe emor tions? If so, would use of these samples be appropriate methodology to study tre neurological basis of pain or the psychologigil basis of major depression or anxiety? Are thefe ethical limits to what could be done with or to these cell masses?

8) Can a person give consent for his or her bragn tissue to be grown or maintained in a laboratory setting if the tissue had or develops the indepenes ent capacity to respond at some level? In son persons with severe epilepsy removal of one hemb sphere of the brain above the brain stem is the treatment of choice. ${ }^{13}$ Surely, even the most ardent scientist, philosopher, or ethicist must reflect wi wonder on the circumstance of a two-hemisphe brain-mind duality deliberating the destruction 8 one-half of itself as a treatment for disease. Is the a difference in the consent for a procedure fro the verbal half of the brain? How would the nowverbal portion of the brain assent to or disse from a given procedure? Post-operative consent by the left hemisphere to experiments carried ovf in vitro, on the right hemisphere, appears to be $\mathbb{C}_{a}$ case of one conscious subject deciding for another, whereas preoperative consent appears be a case of a conscious subject deciding for paigt of itself. Should these issues be a consideration for institutional review boards? Organization of a dis cussion of this issue would need to address seve商. questions:

- What rules of consent would be used if the damaged half of a brain after surgery was to be kept alive and studied?

- Does one half of a brain-mind have a capacion, or the right, to give consent for studies on the other half after it has been removed from the head? Could the diseased half dissent? If so howe? - What if one proposes to study emotions gene ated by stimulation of the diseased half after removal from the body? Is there a limit to t tBe degree of depression or anxiety that could 5 studied? Would it be acceptable to produce severge pain sensations for study?

- Do these same arguments apply to a few cells a laboratory dish? 
- If not, what is a critical mass or at what level of organization does tissue become a brain?

Imagine this discussion with Gillon's theoretical person, Susan. Susan presents for a hemispherectomy for some cause, perhaps uncontrollable epilepsy. ${ }^{13}$ After extensive brain mapping using deep electrode studies, Susan is presented with the interesting option of having her epilepsy substantially improved by a hemispherectomy and also greatly advancing science by consenting for the excised half of her brain to be used for laboratory-based studies. Susan recalls her vivid memories of the deep electrode stimulation of the diseased hemisphere to determine what effect a hemisphectomy would have. She recalls her perception of searing pain with the electrical stimulation of one area, the frightening anxiety provoked by stimulation of a second area, and the profound depression she experienced from stimulation of a third area. These responses are exactly the responses the researchers plan to study in the excised brain tissue. What would be an appropriate response to the following two questions posed by Susan:

"Since that part of my brain will be gone these experiments will not cause me to feel pain, will they? "Will I be aware of these experiments?" Is a person/mind divisible into two fragments that retain the (same or different) person or mind qualities? The scenario of one person/mind fragment consenting to procedures on the other is a difficult dilemma. Currently the person/mind fragment, comprised of brain only if it in fact exists, would be given the same status by an institutional review board as a skin biopsy, a lobe from a lung or a blood sample. Clearly, the person $/ \mathrm{mind}$ fragment in the body retains the original person and mind qualities. What is the status of the former brain tissue? Does it retain some person/ mind qualities? Does it represent a different person and mind?

9) Should a human subjects institutional review board review these activities and how could such a board determine when a person is being studied rather than a collection of neurons? Society and medicine have reached a useful and workable definition of death. The concept of life requires further discussion. The concept of personhood will also require additional thought, discussion and definition if society and the neuroscience community are to develop a general level of agreement about this issue. How is society to come to grips with these issues discussed above? First, should limits be placed on scientists' efforts to develop or maintain living human brain tissue (partial or whole brains)? In what way does the removal of a live functioning brain from a person whose body is destroyed in a road accident (where the sole purpose is the maintenance of the brain for laboratory tests because of the amazing array of responses in this organ) differ from selecting a liver or kidney equally prized for their ability to exhibit biochemical, electrical or structural changes in response to environmental alterations? In the case of liver or kidney, either entire organs or small cell populations, a liver or kidney is all these cells will be. This is not the case with brain tissue. If society forbids, or on the other hand encourages, these activities in the name of science the arguments will encompass both the ethical and scientific domains. Any such discussions will need to be wide ranging. They will need to include consideration of the possibility of greater good for both society and individuals - from continuing with the study of brain tissue, and also of the application of restrictions on these efforts in the name of individual human dignity.

\section{Recommendations}

We offer the following criteria for consideration by ethicists, neuroscientists and human subjects institutional review boards. These recommendations are based on three neurophilosophical considerations:

1. Human nervous tissues and especially brain tissue is unique. Muscle or liver tissues do not have the capacity to develop and support mental activity.

2. In humans, mental activities do not require whole brains.

3. Animal and computer models may provide adequate models for this research.

TRANSPLANTATION - IN VIVO

(1) Until the peripheral nervous system can be re-attached whole brain or whole head transplants should be prohibited. This is not to imply that we endorse these procedures if or when the peripheral nervous system can be re-connected. Our rationale for this proposal is that the brain-mind-person construct should function as a part of a complex interactive system. To isolate the brain is to deprive the person of these essential interactions. The loss of two sensory systems in congenitally deaf-blind people has severe developmental consequences leading to severe mental retardation. It is likely that the loss of all sensory systems will be a neurological and psychological catastrophe. If transplanted early in development these procedures may produce mindless brains. Animal and computer 
models would probably provide appropriate models for this research for some time.

(2) Complete hemisphere transplants should be prohibited until there is reasonable potential for functional linkage of both hemispheres and the transplanted hemisphere to the peripheral nervous system.

\section{BRAIN TISSUE RESEARCH - IN VITRO}

(3) Research on small cell populations should continue. This research is ongoing and small cell populations appear to have limited potential to support mental activities.

(4) If larger brain tissue masses are utilized for research the investigator and human subjects institutional review board should discuss the potential for mental activity. Is mental activity likely to occur or is mental activity the specific focus of the research? If the conclusion is yes, would this research be acceptable from a psychological perspective in a person? If the conclusion is no, the research should not be approved.

(5) Growing substantial masses of brain tissue in laboratory settings should continue. However, neuroscientists and institutional review boards should discuss the potential for mental functioning and make these decisions with the awareness that we do not yet know if this tissue can develop mental activity.

(6) Growing or maintaining complete brains without bodies should be prohibited. Development of necessary technical advances in these areas have grown very rapidly. As in the area of molecular genetics, new developments will quite likely far outpace public thought and discussion on the interface between science and societal ethics on this issue.

\section{Acknowledgement}

We wish to extend our appreciation to the anonymous reviewers whose comments greatly improved this manuscript.
Larry Burd, PhD, MCRH, is Assistant Professom Departments of Neuroscience and Pediatrics, the Uni versity of North Dakota. Fennifer M Gregory, BS, is medical student at the University of North Dakoto? Facob Kerbeshian, MD, is Clinical Professor, Depart? ment of Neuroscience, University of North Dakotc $\frac{\sigma}{\bar{w}}$ Both Dr Burd and Dr Kerbeshian are members of the Altru Health Systems Bioethics Committee.

\section{References}

1 Gillon R. Brain transplantation, personal identity and medică ethics. Fournal of Medical Ethics 1996;22:131-2.

2 Northoff G. Do brain tissue transplants alter personal identity? Inadequacies of some "standard" arguments. fournal of Medical Ethics 1996;22:174-80.

3 Implementation plan for the Decade of the Brain. Neurolog $\overrightarrow{90}$ 1990;40:1483-6.

4 Lin LF, Doherty DH, Lile JD, Bektesh S, Collins F. GDNF: $\underline{a_{1}}$ glial cell line-derived neurolotrophic factor for midbrain dopaminergic neurons. Science 1993;260:1130-2.

5 McMillian MK, Thai L, Hong JS, Callaghan JP, Pennypacker. KR. Brain injury in a dish: a model for reactive gliosis. Trends int Neuroscience 1994;17:138-42.

6 Verdura J, White RJ, Albin MS. Conceptos actuales en ब్రం tratamienta de traumatismos craneocerebrales cerrados. Hom enaje en el XXV Anniversario Professional. Dr M. Velasco Suæo rez, 213 (Mexico) 213-222, 1964.

7 White R J. Experimental transplantation of the brain. In: Rap port FT, Dausset J, eds. Human transplantation. New Yor Grune and Stratton, 1968: 692-709.

8 Madrazo I, Lion V, Torres C, Aquilera DC, Varila G, Alvarey et al. Transplantation of fetal substantia nigra and adrenat medulla to the candate nucleus in two patients with Parkinson? disease. New England fournal of Medicine 1988;318:51.

9 Report of the medical consultants on the diagnosis of death the President's Commission for the Study of Ethical Problenes in Medicine and Biomedical and Biobehavioral Research: Guidelines for the delimination of death. Neurology 1982;3 395-9.

10 Bernot JL. Brain death. Archives of Neurology 1992;49:569-70.ㅁ

11 Katz RT, Haig AJ, Clark BB, DiPaola RJ. Long-term surviva prognosis and life-care planning for 29 patients with chronio locked-in syndrome. Archives of Physical Medicine and Rehabilite? tion 1992;73:403-8.

12 Demikhov VP. Experimental transplantation of vital organs. Net York: Consultants' Bureau, 1962. See also reference 7.

13 Vining EPG, Freeman JM, Pillas DJ, Vematsu S, Carson B\$ Brandt $\mathrm{J}$, et al. Why would you remove half a brain? Tho outcome of 58 children after hemispherectomy - the Johns HoR kins experience 1968 to 1996 . Pediatrics 1997;100:163-71. 